\title{
La caminabilidad en el centro de Río Gallegos. Septiembre 2014
}

\section{Walkability in the center of Río Gallegos. September 2014}

\author{
María Fernanda Puca, Yanina Paola Valdebenito, Karla Lizeth, Aceves Padilla, Alicia P. \\ Cáceres, Patricia Frías \\ ferpuca93@gmail.com,yaninavaldeb80@hotmail.com,lhyzeth@gmail.com, \\ acaceres@uarg.unpa.edu.ar,pfrias@uarg.unpa.edu.ar \\ Universidad Nacional de la Patagonia Austral \\ Unidad Académica Rio Gallegos \\ Escuela de Geografía, Ordenamiento Territorial y Geoinformación \\ Av. Gregores y piloto "Lero" Rivera \\ Santa Cruz, Río Gallegos
}

Recibido: 28/05/2020. Aceptado: 14/12/2020

\begin{abstract}
RESUMEN
El centro de Río Gallegos, presenta una gran variedad de estados de las aceras/veredas en el cual se puede llegar a ocasionar algún tipo de riesgo para el peatón. Este trabajo tiene como finalidad analizar e indagar sobre la Caminabilidad en el centro de Río Gallegos; conocer los parámetros que determinan a este concepto. La Caminabilidad es un concepto contemporáneo que tomó preponderancia luego de que surgieran las ciudades sostenibles en Europa. Esta concepción conlleva a que el espacio público sea más equilibrado entre los medios de transporte y el peatón. Esto requiere a la vez una verdadera implicancia de políticas de urbanización para lograr un ambiente más "caminable". Metodológicamente, la información se obtiene con la recolección de datos a través de la observación directa, donde se aplicaron fórmulas utilizadas por el programa de Excel, y posteriormente es procesada a través de un SIG (Sistemas de Información Geográfica). Los resultados reflejaron datos significativos, obteniendo valoraciones generales de estados desde Muy Malo a Muy Bueno, que posee cada lado de las manzanas del centro de Río Gallegos. Por último, se presentan sugerencias para tomar consciencia sobre el estado del centro de la ciudad, ayudar a la planificación urbana, y al cuidado del centro. A la vez, darle una valoración a este espacio, sabiendo que es un lugar donde transitan muchas personas continuamente.
\end{abstract}

Palabras clave: centro; transeúnte, valoración general, vereda; obstáculo.

\begin{abstract}
The center of Río Gallegos, presents a great variety of states of the sidewalks in which it can get to cause some type of risk for the pedestrian. This work has as purpose the analysis and inquire the walkability in the center of Río Gallegos; know the parameters that determine the concept. Walkability is a contemporary notion that took precedence after the emergence of sustainable cities in Europe. This concept leads the public space to become more balanced between the means of transport and the pedestrian. At the same time, this requires a true implication of urbanization policies to achieve a more "walkable" environment. Methodologically, the information is obtained through data collection with direct observation, where formulas used by the Excel software were applied, and it was subsequently processed
\end{abstract}


through a GIS (Geographic Information Systems). The results reflect significant data, obtaining general evaluations of states from Very Bad to Very Good, which have each side of the blocks in the center of Río Gallegos. Finally, suggestions are presented to raise awareness about the state of the city center, help urban planning, and care for the center. At the same time, value this space, knowing that it is a place where many people pass continuously.

Keyword: center; passerby; overall rating; sidewalk; obstacles.

\section{INTRODUCCIÓN}

El presente trabajo se realizó en el mes de septiembre de 2014 en el marco de la cátedra Metodología de la Investigación en Geografía, correspondiente al tercer año de las carreras Profesorado y Licenciatura en Geografía, de la Universidad Nacional de la Patagonia Austral, Unidad Académica Río Gallegos.

La finalidad del trabajo fue analizar la Caminabilidad del centro de Río Gallegos debido a que se observa, a simple vista, una gran variedad de estados de las aceras/veredas, en las cuales se puede llegar a ocasionar algún tipo de accidente para el peatón.

Por tal motivo, desde la cátedra, se planteó la siguiente pregunta de investigación ¿La Caminabilidad es óptima en el centro de Río Gallegos? y como hipótesis, se considera que la Caminabilidad no es óptima en el centro de Río Gallegos.

Se plantearon objetivos para llevar a cabo la investigación. En primer lugar, con respecto a los objetivos generales, se desarrollaron los siguientes: indagar y conocer la Caminabilidad en el centro de Río Gallegos y en segundo lugar, como objetivo específico, determinar, a partir de los parámetros establecidos, si es óptima la Caminabilidad en el centro de Río Gallegos.

La Caminabilidad es un concepto contemporáneo que tomó preponderancia luego de que surgieran las ciudades sostenibles en Europa. Este concepto conlleva al espacio público ser más equilibrado entre los medios de transporte y el peatón, esto requiere, a la vez, una verdadera implicancia de políticas de urbanización para lograr un ambiente más "caminable".

Cuidar todos los espacios públicos con un trato favorable para quienes tienen movilidad reducida es uno de los retos fundamentales de la accesibilidad, de manera de convertir la ciudad en más amable y más agradable, no sólo para las personas en silla de ruedas, sino también para todos los transeúntes que tienen dificultades para desplazarse tales como: ancianos, mujeres embarazadas, niños, personas con bebés en carritos, personas con muletas, etc.

Determinar las buenas reglas como: ancho mínimo de espacio de paso, pendientes máximas, desniveles máximos aceptables, calidad de los espacios y señalización especial en cada caso, etc., asegura que el espacio público se convierte en un lugar mucho más agradable y seguro.

Metodológicamente, en primer lugar, se realizó una investigación bibliográfica sobre el tema y se seleccionó la información pertinente. En segundo lugar, se llevó a cabo una construcción de los parámetros a medir y sus respectivas planillas para su posterior relevamiento. En tercer lugar, se obtienen datos a través de la observación directa en el campo de estudio. Por último, se realiza el procesamiento de los datos a través de fórmulas utilizadas en una hoja de cálculos, "Excel” y en un SIG (Sistema de Información Geográfica). 


\section{MARCO DE REFERENCIA}

\subsection{MARCO HISTÓRICO - GEOGRÁFICO}

\section{Río Gallegos como espacio geográfico}

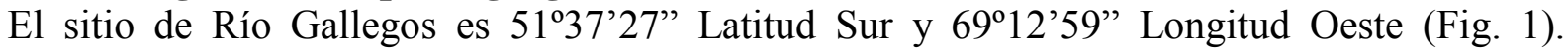
Localizada en el extremo SE de Santa Cruz, la provincia más austral de la Argentina continental; es una ciudad intermedia por reunir funciones propias de una capital provincial. Situada en el área costera, donde se localiza más del $66 \%$ de la población provincial, comunicada por la Ruta Nacional $\mathrm{N}^{\circ} 3$, paralela a la costa atlántica. Estas localidades costeras se emplazan en estuarios o diferentes accidentes geográficos (bahía, caletas). El interior provincial está comunicado por la Ruta Nacional $\mathrm{N}^{\circ} 40$, paralela a la cordillera. (Cáceres et al., 2016:47).

Siguiendo con los mismos autores, el tipo de clima es frío semiárido de meseta, con vientos predominantes del sector oeste-sudoeste, la latitud es un condicionante de la vida urbana puesto que corresponde a la zona de libre circulación atmosférica y oceánica; que explica la presencia de vientos fuertes del oeste, la falta de verano térmico y los días largos del verano y las noches largas del invierno.

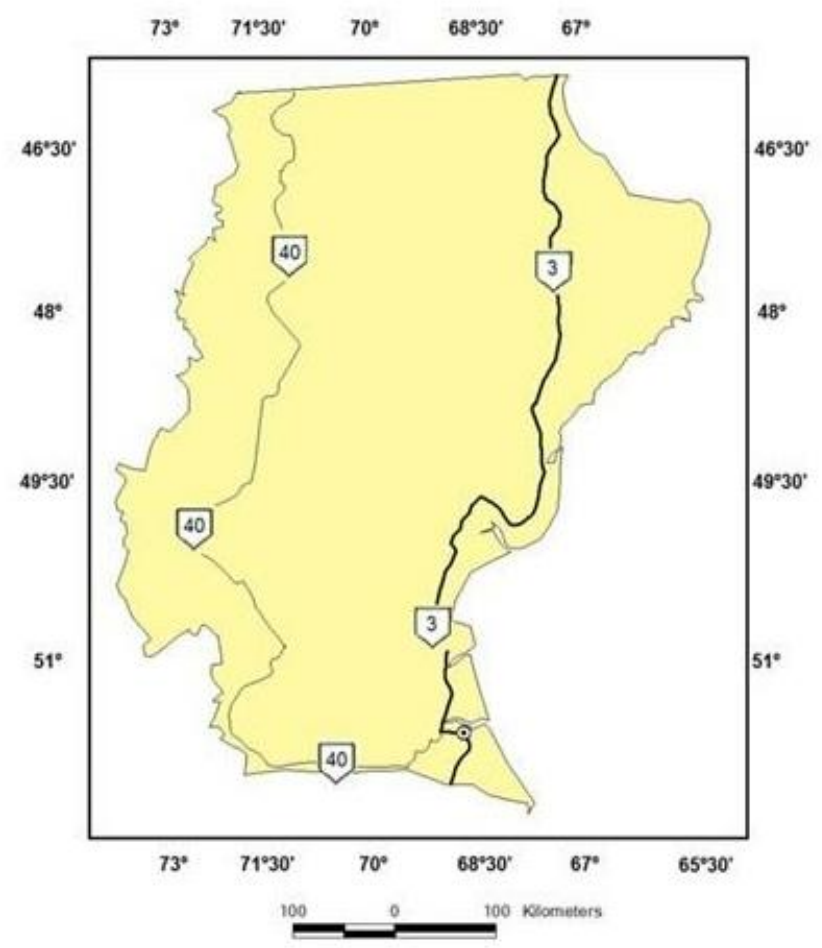

Rutas Nacionales

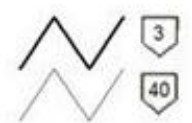

๑ Rio Gallegos

Santa Cruz

Figura 1: Localización de Río Gallegos

Fuente: Elaborado por Puca, M. F., Valdebenito, Y. y Aceves, K. L.

\subsection{MARCO CONCEPTUAL}

El concepto "Caminabilidad" presenta distintas definiciones: por un lado, surge de la traducción de walkability. Litman $(2003)^{1}$, describe el valor económico del hábito de la caminata, o como él mismo define, el no uso del automóvil y otro medio de transporte que

\footnotetext{
${ }^{1}$ En Bezerra y Tapia. "La Caminabilidad de las ciudades como un reflejo del desarrollo sustentable".
} 
consuma combustible de fuentes no renovables y poluentes, deja de manera implícita, en este concepto, el valor del uso de las bicicletas. De acuerdo con el autor, el hábito de la caminata no es fácil de ser medido y por eso tiende a ser subestimado en las decisiones de planeamiento urbano de los organismos oficiales. En este ámbito, es privilegiada la construcción de calles y estacionamientos, en detrimento de la creación de vías peatonales (Bezerra y Tapia, 2004).

Desde una mirada de Políticas Públicas y Economista, Alejandra Leal, entiende la Caminabilidad como la descripción y medición de la calidad de las vías peatonales en las ciudades. Según el Banco Interamericano de Desarrollo plantea que es una medida de cuán fácil es un área para un peatón.

En esta instancia, entonces, dado el grado de tecnicismos empleados, para entender el trabajo desarrollado, se presentan los conceptos relacionados a la medición de la Caminabilidad que son necesarios para evitar ambigüedades y que han sido extraídos de la Real Academia Española (RAE), de leyes, decretos nacionales sobre seguridad vial y construcción edilicia en la República Argentina.

Uno de los principales conceptos a tener en cuenta es el de "vía pública", el cual se puede definir como los caminos que pueden ser utilizados para marchar por ellos, abiertos al tráfico y regulados por las normas de circulación.

En relación a la estructura vial, y de manera general, la información consultada plantea que toda obra o dispositivo que se ejecute, instale o esté destinado a surtir efecto en la vía pública, debe ajustarse a las normas básicas de seguridad vial, propendiendo a la diferenciación de vías para cada tipo de tránsito y contemplando la posibilidad de desplazamiento de discapacitados con sillas u otra asistencia ortopédica. Cuando la estructura vial no pueda adaptarse a las necesidades de circulación, ésta deberá desenvolverse en las condiciones de seguridad preventiva que imponen las circunstancias actuales. Estas obras o dispositivos existentes en la vía pública pueden ser: una acera o vereda con cierta pendiente o no, una ochava, un cartel publicitario, una rampa, servicios de señalamientos, vehículos, cualquier obstáculo, canteros, etc.

Se entenderá acera, vereda, banqueta o andén, a la superficie pavimentada a la orilla de una calle u otras vías públicas para uso de personas. Usualmente se sitúa a ambos lados de la calle $^{2}$. La zona de la vía destinada solo a la circulación de vehículos recibe el nombre de calzada. ${ }^{3}$ En el sector de la acera se puede encontrar un área delimitada por barreras o paredes de distintos materiales, ya sea madera, concreto u otra que encierre el sustrato, impidiendo su desplazamiento y facilitando su manejo y conservación, llamado cantero. Es un camino para peatones que se sitúa a los costados de una calle o espacios públicos. De acuerdo a la legislación vigente si una vereda presenta una diferencia de nivel con respecto a una subsiguiente, la transición entre ambas se hará por medio de un plano inclinado y en ningún caso por medio de escalones. ${ }^{4}$

Dentro de la acera, podemos encontrar diferentes elementos:

- El cartel publicitario, que frecuentemente se encuentra en las veredas, es el soporte de la publicidad y consiste en una lámina de papel, cartón u otro material que se imprime con algún tipo de mensaje visual (texto, imágenes y todo tipo de recursos gráficos) que

\footnotetext{
${ }^{2}$ Real Académica Española. RAE

${ }^{3}$ Leyes y decretos de la seguridad vial en Argentina 2012. Pág. 15

${ }^{4}$ Zalazar, Flor. (2014). Condiciones y normas que debe tener una vereda. Prezi.
} 
sirve de anuncio para difundir una información, un evento, un bien económico (ya sea producto o servicio), una reivindicación o cualquier otra causa.

- La senda peatonal es el sector de la calzada destinado al cruce de ella por peatones y demás usuarios de la acera. Si no está delimitada, es la prolongación longitudinal de ésta ${ }^{5}$.

- La ochava es el recorte obligatorio que los propietarios deben hacer de sus edificios y terrenos ubicados en la esquina de una manzana ${ }^{6}$.

- El solado es la orilla de la calzada, generalmente enlosada, situada junto al paramento de las casas, destinada para el tránsito de la gente que va a pie. ${ }^{7}$

La vía pública cuenta con un sistema de señalización vial uniforme que es la descripción, significado y ubicación de los dispositivos de seguridad y control del tránsito, reglamentados con las especificaciones técnicas y normalización de materiales y tecnologías de construcción y colocación y demás elementos que hacen a la calidad y seguridad de la circulación vial. Brinda información a través de una forma conveniente y unívoca de comunicación, destinada a transmitir al usuario de la vía pública órdenes, advertencias, indicaciones u orientaciones, mediante un lenguaje que debe ser común en todo el país, según los principios internacionales. Con el fin de mantener el criterio de unicidad y complejidad, se incluyen señales (como las realizadas mediante barreras o semáforos ferroviales) propias del sistema operativo del ferrocarril, pero destinadas a la circulación carretera. ${ }^{8}$ El Señalamiento vertical son señales de regulación del tránsito, destinadas en su gran mayoría a los conductores de los vehículos, colocadas al costado de la vía o elevadas sobre la calzada (aéreas). ${ }^{9}$ Y el Señalamiento horizontal son las señales de tránsito demarcadas sobre la calzada, con el fin de regular, transmitir órdenes, advertir determinadas circunstancias, encauzar la circulación o indicar zonas prohibidas. ${ }^{10}$

El Servicio de transporte es el traslado de personas o cosas realizado con un fin económico directo (producción, guarda o comercialización) o mediando contrato de transporte ${ }^{11}$. El lugar señalado para el ascenso y descenso de pasajeros del servicio pertinente, se define como parada. $^{12}$

La rampa son soluciones complementarias a las escaleras, y son fundamentales para que los usuarios de sillas de ruedas puedan acceder a los distintos niveles, pero además resultan muy útiles para poder circular con maletas, coches de niños, carros, etc.

Tomando los aportes de Florencia Ucha, el transeúnte es el individuo o peatón, que camina o transita por un determinado lugar. Su recorrido puede ser afectado por obstáculos, definidos como "un impedimento, un inconveniente o una dificultad" según la RAE.

A partir de la presencia de los obstáculos en las aceras, se realizará un intervalo de valoración de la caminabilidad, cuantificando los elementos que se releven en las salidas de campo, los cuales pueden ser: baldosas (mal estado o ausencia), escalones (sin señalización), canteros (sin mantenimiento), acción biológica (raíces de árboles), etc.

\footnotetext{
${ }^{5}$ Leyes y decreto. Ley 24.449. pág. 16

${ }^{6}$ Enciclopedia de ciencia y tecnología en Argentina.Concepto de ochava. Sitio web: cyt-ar.com.ar

${ }^{7}$ Minaya J. H. Omar. (2009). Informe sobre: Tratamiento de Veredas. Universidad César Vallejo.

${ }^{8}$ Leyes y decretos. Ley 24.449. Anexo al artículo 22. Anexo L. Pág. 315.

${ }^{9}$ Leyes y decretos. Ley 24.449. Anexo L. Pág. 317.

${ }^{10}$ Leyes y decretos. Ley 24.449. pág. 347

${ }^{11}$ Leyes y decretos. Ley 24.449. pág. 16

${ }^{12}$ Leyes y decretos de la seguridad vial Argentina 2012. Pág. 15
} 
Este recorrido realizado por el transeúnte, si no se encuentra con obstáculos, se definirá como una Caminabilidad de carácter "óptimo": del superlativo bueno; (lat. optimus), adjetivo que indica "sumamente bueno" o "que no puede ser mejor. ${ }^{13}$

El riesgo es la probabilidad de que un peligro se materialice en determinadas condiciones y genere daños a las personas, equipos y ambientes. Para que se produzca un daño debe ocurrir un evento adverso, un riesgo, que puede ser endógeno o exógeno, una incapacidad de respuesta frente a él, y una inhabilidad para adaptarse al nuevo escenario generado por la materialización del riesgo. ${ }^{14}$

\subsection{MARCO TEÓRICO}

Las investigaciones sobre Caminabilidad se centran en explicar cuáles son los aspectos a mejorar en el entorno de una determinada ciudad, con el fin de lograr que la población adquiera hábitos más saludables.

En el método que utilizan tienen en cuenta aspectos como el acceso espacial a las instalaciones ya sean construidas o naturales, las características del medio ambiente funcional (por ejemplo: existencia de sendas peatonales, tipo de calles, tiendas, etc.) o la cobertura arbórea. En general, en varias investigaciones, hay determinados atributos que son comunes en los artículos, ya que pueden tener una influencia más directa en el índice de "Caminabilidad". Por ejemplo, Owen et al. (2007) realizaron un análisis a partir del SIG para crear dicho índice e identificar las variaciones existentes entre los barrios seleccionados para el estudio en la ciudad de Adelaida (Australia). El índice se calculó a nivel de distrito, utilizando como atributos ambientales: la densidad de vivienda, la conectividad de la calle, la mezcla de los usos del suelo y la zona comercial neta. Pero no tienen en cuenta aspectos como el acceso a zonas recreativas o la calidad del medioambiente peatonal (por ejemplo: mantenimiento de la acera o la estética). Los resultados obtenidos sugieren que la población que vive en ambientes que son calificados como más transitables, podrían tender a realizar más viajes a destinos cercanos, lo que podría tener como consecuencia la reducción de los viajes de vehículos de motor.

Saelens et al. (2003) en su artículo Environmental correlates of walking and cycling: findings from the transportation, urban design, and planning literatures, utiliza principalmente dos conceptos en el índice de Caminabilidad, similares al anterior estudio: la proximidad o distancia, que está determinada por la densidad de los usos del suelo y su mezcla, y la conectividad entre el punto de partida y el de destino, que mide la inmediatez de la vía entre calles, tiendas y lugares de trabajo. Por ejemplo, con respecto a este último atributo, cuando hay muchas calles con muchas interconexiones, con un patrón establecido de cuadrícula regular, se facilita el caminar. Con ello, llega a la conclusión de que cuanto más compacta sea la zona y más variedad de usos hay, más corta será la distancia entre el inicio y destino de un determinado trayecto.

Leslie, et al., (2007) toma los aportes de Humpel et al. (2004) donde a través de encuestas telefónicas llegaron a la conclusión de que vivir en una zona costera está asociado a la existencia de una mayor probabilidad de caminar. Los atributos que utilizaron para su análisis, fueron la estética del barrio, el tráfico, la comodidad de las instalaciones y el acceso a los

\footnotetext{
${ }^{13}$ RAE

${ }^{14}$ Foschiatti, Ana María. Vulnerabilidad global y pobreza. Universidad Nacional del Nordeste. Vulnerabilidad global y pobreza. Sitio web: hum.unne.edu.ar
} 
servicios. Principalmente determinan que una mejora en la comodidad percibida del entorno de vecindad puede estar asociada al aumento del tiempo del trayecto que se hace caminando.

Los otros atributos que utilizan son comunes en todas las investigaciones, por ejemplo: la densidad de la vivienda, la conectividad, los usos del suelo, su zonificación o la superficie comercial, la presencia de parques o centros recreativos; presencia, condición y continuidad de los caminos; las distancias existentes a las instalaciones; la accesibilidad de tránsito; factores relacionados con las características naturales, como la topografía o barreras físicas; y otros aspectos del diseño urbano, como el diseño de edificios y su orientación, el alumbrado, oficinas de correos, el transporte público o parques; la presencia de rutas de senderismo /ciclismo; la seguridad del entorno, tanto en lo referente a la densidad de tráfico motorizado como el riesgo de crimen; el acceso a determinadas área como son los playas, destinos recreativos que no están atravesados por carreteras, y que exista una continuidad en la red de calles o caminos.

En lo concerniente a la "Caminabilidad" de los entornos urbanos, principalmente resulta interesante lo relacionado con aquellos atributos que hacen que un entorno sea más agradable o atrayente para el caminante. Pues, como se verá, las características del entorno tienen un peso muy importante en la elección de una ruta u otra por parte de la población.

¿Y por qué es importante analizar y desarrollar trabajos sobre "Caminabilidad" en las ciudades? Porque, unido al uso de la bicicleta, ambos suponen uno de los elementos claves en la recuperación de los entornos urbanos modernos, así como notables mejoras en la salud de sus habitantes $\mathrm{y}$, por lo tanto, que se pueda conseguir que la ciudad sea sinónimo de sostenibilidad ambiental. En lo referente a la recuperación y mejoras en el entorno urbano, el análisis de los atributos de este en relación con la "Caminabilidad", pueden ayudar a que la planificación de determinadas zonas o barrios se lleve a cabo de la forma más adecuada. Por ejemplo: puede ayudar a establecer dónde concentrar las inversiones o donde existen oportunidades para aumentar la actividad física, así como aspectos más concretos, como es el caso de la detección de aquellos lugares que tienen una buena conectividad. En definitiva, el desafío radica en identificar las correlaciones más destacadas de la "Caminabilidad" para guiar la creación de entornos peatonales (Leslie et al. 2007) y que este tipo de movilidad se integre en la elaboración y seguimiento de las políticas de movilidad urbana (Secretaria de Estado de Transporte, 2010). Estos entornos peatonales suelen identificarse con la presencia de aceras, pero son muchos otros elementos los que hacen que una zona sea calificable como peatonal y que, por lo tanto, no exista una forma precisa de describirlos. En forma general, investigar y realizar un índice de "Caminabilidad" para una determinada ciudad o zona, va a ser muy beneficioso, tanto para el entorno como la población que reside y camina en él. Y si estos estudios se los introducen y combinan con otros, como pueden ser los planes de movilidad urbana, el objetivo de una ciudad sostenible estará más cerca que nunca.

Las aceras son otro concepto de relevancia en este estudio, como se enunció anteriormente, una acera con fluidez ofrece un ancho de vía y un espacio libre compatible con el flujo de los peatones que la utilizan normalmente, de esta forma, consiguen andar a una velocidad constante. Una acera que ofrece confort debe presentar un piso parejo y antideslizante (aun cuando está mojado) y no presentar obstáculos dentro del espacio libre, que obliguen a los peatones a desviarse de su camino. Una acera con seguridad no puede presentar riesgo de caída o tropiezo para los peatones. Otros aspectos que pueden determinar la calidad de las aceras son: 
- Inclinación: los paseos deben ser construidos de forma de dar comodidad a todos los peatones, tratando de que su arquitectura sea lo más plana que, en la práctica, sea posible.

- Rampas: son deseables en todos los cruces, tanto en las intersecciones como en las "entrecuadras". Las rampas dan comodidad, no solamente a las personas en silla de ruedas sino también a los peatones, personas con bebés en carritos y ancianos.

Otra alternativa son los "lomos de burro" (elevaciones de la vía vehicular) y "las cebras" en el cruce de peatones, pues generan una reducción de la velocidad de los automóviles, y así, una mayor seguridad para los usuarios, principalmente en el cruce de escolares.

- Obstáculos a lo largo de la vía: pueden no ser identificados por los peatones, principalmente los deficientes visuales.

Obstáculos aéreos deben ser retirados de la ruta de los peatones: deben estar a una altura mayor de 2,1 metros.

- Iluminación: una buena iluminación pública aumenta la visibilidad, el confort y la seguridad pública de los peatones que hacen uso de las aceras en la noche.

Para promover la caminata es necesario ofrecer aceras adecuadas para el tránsito de ancianos, personas con deficiencias físicas (permanentes o temporales) y personas con bebés en carritos. Implementos tales como señales sonoras en los cruces de peatones, rampas con pendiente adecuada, etc. deben ser instalados. No basta simplemente con tener una rampa, si ésta es intransponible para el usuario de silla de rueda que viaja solo. Pequeñas mejoras en las condiciones de las aceras conllevan a incentivar el hábito de la caminata en los centros urbanos. (Bezerra y Tapia, 2004).

Luego de esta revisión de enfoques teóricos, se adoptarán para esta investigación los aportes de Leslie et al. (2007), citado en Fontán Suárez (2012:7), los cuales definen el concepto de Caminabilidad como:

"la medida en que las características del entorno construido y el uso del suelo pueden o no ser propicias para movimientos de a pie para los residentes de una determinada zona, ya sea para desarrollar actividades de ocio, ejercicio o la recreación, o para acceder a los servicios, viajar o trabajar. Como se verá, son las propias características del entorno, las que van a posibilitar que una determinada persona o grupo de personas decidan caminar por una calle determinada y no por otras, por lo que es muy importante e interesante analizarlas, con el fin de observar en qué grado influyen y cómo lo hacen en los distintos aspectos de nuestra vida cotidiana".

\subsection{MARCO LEGAL}

Desde el año 1995 rige en la República Argentina la Ley Nacional de Tránsito y Seguridad Vial N²4449 (sancionada el 23 de diciembre de 1994, promulgada parcialmente el 6 de febrero de 1995) y su Decreto reglamentario $\mathrm{N}^{\circ} 779 / 95$ cuyas previsiones fueron insuficientemente implementadas y rezagadas por el vertiginoso avance tecnológico y el aumento exponencial del parque automotor. En este contexto fue, que, en el mes de abril del año 2008 se sanciona la Ley $N^{\circ} 26363$, la cual, crea la Agencia Nacional De Seguridad Vial, como autoridad de aplicación de las políticas y medidas de seguridad vial nacionales previstas en la normativa vigente, con la misión de reducir la tasa de siniestralidad en el territorio 
nacional, mediante la promoción, coordinación, control y seguimiento de las políticas de seguridad vial, nacionales e internacionales.

Posteriormente en octubre del año 2008, se reglamenta esta ley por el Decreto $\mathrm{N}^{\circ} 1716 / 08$, organizándose la actividad prevista y dotando al organismo responsable de los recursos pertinentes al efecto. De esta manera la política en seguridad vial del Estado Nacional se encuentra debidamente regulada y está siendo encaminada a lo largo de todo el territorio Argentino, en consenso con las autoridades competentes de todas las jurisdicciones y en consonancia con la sociedad civil representada por las entidades privadas vinculadas por medio del Comité Consultivo de la Agencia Nacional de Seguridad Vial.

\section{La Vía Pública.}

Estructura Vial: toda obra o dispositivo que se ejecute, instale o esté destinado a surtir efecto en la vía pública, debe ajustarse a las normas básicas de seguridad vial, propendiendo a la diferenciación de vías para cada tipo de tránsito y contemplando la posibilidad de desplazamiento de discapacitados con sillas u otra asistencia ortopédica. Cuando la estructura vial no pueda adaptarse a las necesidades de circulación, ésta deberá desenvolverse en las condiciones de seguridad preventiva que imponen las circunstancias actuales. ${ }^{15}$

Sistema uniforme de señalamientos: la vía pública será señalizada y marcada conforme al sistema uniforme que se reglamente de acuerdo con los convenios internos y externos vigentes. Solo son exigibles al usuario las reglas de circulación, expresadas a través de las señales, símbolos y marcas del sistema de señalamiento vial. La colocación de señales no realizada por la autoridad competente, debe ser autorizada por ella. ${ }^{16}$

Obstáculos: cuando la seguridad y/o fluidez de la circulación estén comprometidas por situaciones u obstáculos anormales, los organismos con facultades sobre la vía deben actuar de inmediato según su función, advirtiendo del riesgo a los usuarios y coordinando su accionar a efectos de dar solución de continuidad al tránsito. Toda obra en la vía pública destinada a reconstruir o mejorar la misma, o a la instalación o reparación de servicios, ya sea en zona rural o urbana y en la calzada o acera, debe contar con la autorización previa del ente competente, debiendo colocarse antes del comienzo de las obras los dispositivos de advertencia establecidos en el sistema uniforme de señalamiento. Cuando por razones de urgencia en la reparación del servicio no pueda efectuarse el pedido de autorización correspondiente, la empresa que realiza las obras también deberá instalar los dispositivos indicados en el Sistema Uniforme de Señalamiento Vial, conforme a la obra que se lleve a cabo. Durante la ejecución de las obras en la vía pública debe preverse paso supletorio que garantice el tránsito de vehículos y personas y no presente perjuicio o riesgo. Igualmente se deberá asegurar el acceso a los lugares sólo accesibles por la zona en obra. El señalamiento necesario, los desvíos y las reparaciones no efectuadas en los plazos convenidos por los responsables, serán llevados a cabo por el organismo con competencia sobre la vía pública o la empresa que ésta designe, con cargo a aquéllos, sin perjuicio de las acciones que se establezcan en la reglamentación por los incumplimientos. ${ }^{17}$

Por otro lado, la Administración General de Vialidad Provincial en la Ley de Tránsito dice:

\footnotetext{
${ }^{15}$ Leyes y decretos viales. Ley 24.449. Artículo 21. Pág. 23-24.

${ }^{16}$ Leyes y decretos viales. Ley 24.449. Artículo 22. pág. 24.

${ }^{17}$ Leyes y decretos. Ley 24.449. Artículo 23. pág. 24-25
} 
Artículo 23.- Obstáculos.- Queda prohibida la instalación de elementos agresivos en la calzada, que por sus características atenten contra la seguridad del usuario de la vía. Sólo se podrán instalar aquellos que por su diseño no agredan ni provoquen incomodidad al mismo, circulando a la máxima velocidad permitida en la vía donde dicho elemento se instale. Esta velocidad debe ser adecuada a la función de la vía, dentro de la jerarquización de la red vial. El ente vial competente es autoridad de aplicación en este aspecto. Las zanjas o pozos abiertos en los lugares para circulación peatonal o vehicular estarán delimitadas por vallas o elementos debidamente balizados, de manera de permitir su oportuna detección ${ }^{18}$.

Artículo 25. -Restricciones al dominio. Es obligatorio para propietarios de inmuebles lindantes con la vía pública:

a) Permitir la colocación de placas, señales o indicadores necesarios al tránsito;

b) No colocar luces ni carteles que puedan confundirse con indicadores al tránsito;

c) Mantener en condiciones de seguridad, toldos, cornisas, balcones o cualquier otra saliente sobre la vía;

d) No evacuar a la vía aguas servidas, ni dejar las cosas o desperdicios en lugares no autorizados;

e) Colocar en las salidas a la vía pública, cuando la cantidad de vehículos lo justifique, balizas de luz amarilla intermitente, para anunciar sus egresos;

f) Solicitar autorización para colocar inscripciones o anuncios visibles desde vías rurales o autopistas, a fin de que su diseño, tamaño y ubicación, no confundan ni distraigan al conductor.

g) Tener alambrados que impidan el ingreso de animales a la zona del camino. ${ }^{19}$

Artículo 26.- Publicidad en la vía pública.

a) Salvo las señales del tránsito y obras de la estructura vial, todos los demás carteles, luces, obras y leyendas, sin excepciones, solo podrán tener la siguiente ubicación respecto de la vía pública: en zona urbana pueden estar sobre la acera y calzada. En este último caso, sólo por arriba de las señales de tránsito, obras viales y de iluminación. En ningún caso se podrán utilizar como soporte los árboles, ni los elementos ya existentes de señalización, alumbrado, transmisión de energía y demás obras de arte de la vía. ${ }^{20}$

Artículo 38. Peatones y discapacitados:

Los peatones transitarán:

a) en zona urbana: únicamente por la acera y otros espacios habilitados para ese fin; en las intersecciones, por la senda peatonal; excepcionalmente por la calzada, rodeando el vehículo, los ocupantes del asiento trasero, sólo para el ascenso-descenso del mismo. ${ }^{21}$

\footnotetext{
${ }^{18}$ Anexo 1. Reglamentación General de la Ley 24,449 Tránsito y Seguridad Vial.

${ }^{19}$ Leyes y decretos. Ley 24.449. Artículo 25. pág. 25-26

${ }^{20}$ Leyes y decretos. Ley 24.449. Artículo 26. pág. 26

${ }^{21}$ Leyes y decretos. Ley 24.449. artículo 38. pág. 34.
} 
Cuando no existiera senda peatonal habilitada exclusivamente para personas con discapacidad se considera tal a la franja imaginaria sobre la calzada, inmediata al cordón, que comunica la rampa con la senda peatonal. ${ }^{22}$

Artículo $5^{\circ}$ inc. $t$ de la Ley de Tránsito: Senda Peatonal.

a) Conformación física: Franja o zona sobre la calzada transversal al sentido de la circulación, delimitada por dos líneas paralelas blancas de trazo continuo o discontinuo; o indicada por franjas blancas paralelas al sentido de circulación (cebrado). En este último caso son rectángulos de cuatro décimas de metro a cinco décimas de metro $(0,4$ a $0,5 \mathrm{~m})$ de ancho por tres metros $(3 \mathrm{~m})$, como mínimo, de largo, alineados y paralelos a la acera y separados entre sí por un espacio similar, que conforman una franja o senda que atraviesa la calzada de vereda a vereda. Cuando la encrucijada no es cruce recto, la franja no resulta necesariamente perpendicular a la acera.

b) Significado: Es la zona autorizada para que los peatones crucen la calzada, sin que les sea permitido detenerse o esperar sobre la misma, sobre la que tienen prioridad respecto de los vehículos, salvo cuando existe semáforo o autoridad competente que le indica lo contrario. Los vehículos no deben estacionar ni detenerse sobre ella, ni aún por circunstancias del tránsito.

c) Ubicación: El cebrado deberá utilizarse cuando el volumen de flujo peatonal se considere importante o peligroso, cuando se encuentren alejadas de las intersecciones, o en zona rural. En general la senda debe colocarse como continuación de la vereda de la vía transversal, pero alejándose un metro $(1 \mathrm{~m})$, por lo menos, hacia afuera de la encrucijada, desde la continuación imaginaria del cordón de aquélla vía. Cuando el volumen de giro de los vehículos lo justifique, la senda se debe alejar varios metros de la encrucijada, para permitir la detención antes de ella de los vehículos que giran (bolsón de tránsito) sin que interrumpan el paso de peatones.

d) Observaciones: Cuando en una cuadra existe una senda demarcada, los peatones deben utilizarla obligatoriamente. Cuando no existe se considera tal continuación imaginaria sobre la calzada de la acera transversal (Artículo $5^{\circ}$ inc. $t$ de la Ley de Tránsito).

\section{Ley Provincial de Edificación}

De las Ochavas.

Obligación de formar ochavas. Es de utilidad pública la formación o ensanche, según los casos, de las ochavas. La dimensión de las ochavas quedará determinada tomando, a partir del punto de intersección de las líneas municipales, cuatro (4) metros lineales sobre ambas, sea cual fuere el ángulo que ellas formen entre los límites del $0^{\circ}$ a $135^{\circ}$, cuando el ángulo sea mayor de $135^{\circ}$ - la ochava podrá suprimirse. En casos especiales como avenidas, calles de mucho tránsito, la medida de la ochava quedará supeditada al criterio que fije la Municipalidad.

Apoyo por fuera de la Línea Municipal de Ochava.

Por fuera de la Línea Municipal de ochava y para soportar salientes de pisos altos, se podrá emplazar apoyos en las aceras con las siguientes limitaciones:

${ }^{22}$ Anexo 1. Reglamentación General de la Ley 24,449 Tránsito y Seguridad Vial. 
a) la sección transversal del apoyo se podrá inscribir en una circunferencia de $0.50 \mathrm{~m}$ de diámetro máximo, sin rebasar estos límites.

b) Existirá un paso libre del apoyo a la edificación no menos de dos (2) metros y, respecto del filo del cordón de la calzada, no menos de $0.80 \mathrm{~m}$.

De los cercos y aceras.

Generalidades sobre los cercos:

Obligación de conservar y construir cercos de frente. Todo propietario de un terreno baldío o edificado que no contara con fachada sobre la Línea Municipal está obligado a la construcción y conservación en buen estado del cerco correspondiente, debiendo esto ser observado como principio no omisible ${ }^{23}$ que hace a las normas de la composición urbana.

En predios que contengan en su interior construcciones o depósitos de materiales de aspecto antiestéticos, la Municipalidad podrá disponer la construcción del cerco hasta una altura de tres (3) metros para impedir las visuales desde la vía pública; el mismo debe ser ejecutado en material opaco. En predios baldíos, serán de material opaco, con una altura mínima de un metro ochenta $(1.80 \mathrm{~m})$ debiendo preverse el fácil acceso y limpieza del mismo. En predios edificados, cuando la composición arquitectónica lo permita, el estilo tipo y altura de cada cerco es libre, debiendo los materiales ajustarse a alguno de los siguientes materiales:

Los cercos pueden ser construidos utilizando los siguientes materiales:

-Albañilería común.

-Hormigón simple y armado.

-Verjas de caño, hierro o madera dura trabajados.

-Marcos con alambre tejido artístico.

-Sistema de hormigón premoldeados.

-Combinación de los materiales citados precedentemente.

-Cualquier otro material que se proponga y sea aceptado por la Municipalidad.

Generalidades sobre las aceras:

Celeridad en la ejecución de las aceras. Todo propietario, está obligado a la construcción y mantenimiento de las aceras correspondiente a su frente y su lote.

La construcción o reparación de las aceras deberá efectuarse lo más rápido posible, de modo que no se entorpezca el tránsito más de lo indispensable. En aceras de ancho igual o mayor que 2 metros, la ejecución del solado se hará por mitades, en 2 etapas para facilitar el tránsito de peatones.

Los materiales resultantes de la construcción o reparación de las aceras deberán quitarse en el día dejando la calzada limpia, permitiéndose solo preparar las mezclas en las calles en sitios inmediatos al cordón cuando razones de tránsito no lo impidan.

La protección provisional de la acera en construcción, no podrá ser con alambres tendidos. Se podrá hacer una protección de cintas de material plástico con colores contrastantes tendidas

${ }^{23}$ En la ordenanza aparece como "omitible". 
horizontalmente, convenientes separadas, a partir de $0,10 \mathrm{~m}$. del solado y hasta una altura mínima de $0.90 \mathrm{~m}$.

Artículo 118 Ancho de Acera y solado.

Las aceras destruidas, total o parcialmente, a consecuencia de trabajos realizados por la Municipalidad, empresas de servicios públicos o personas o empresas contratistas de trabajos públicos o privados y autorizadas, serán reparadas o reconstruidas inmediatamente por el causante, con materiales iguales a los existentes antes de su destrucción, en un defecto la notificación correspondiente. El propietario podrá denunciar ante el Municipio, la necesidad de la reparación o construcción.

Será obligatorio la reconstrucción o reparación de la acera, a juicio del Municipio, que no se encuentra al nivel que le fue fijado, en caso de una renovación del pavimento.

\section{OBLIGACIONES ESPECÍFICAS EN MATERIA DE SECRETO ESTADÍSTICO.}

\section{ESTADÍSTICA Y CENSOS LEY N 17.622.}

La ley regula el funcionamiento de la actividad estadística en el ámbito oficial. Incluyendo en su articulación normas estrictas sobre la obligación de tratar con reserva la información individual.

“Artículo 13- Todas las personas que por razón de sus cargos o funciones, tomen conocimientos de datos estadísticos o censales, están obligados a guardar sobre ellos absoluta reserva."

El secreto estadístico o confidencialidad de la información estadística es el resguardo legal que tiene toda persona física o jurídica, obligada a proporcionar datos a los servicios que integran el Sistema Estadístico Nacional, de que esos datos no serán utilizados con otros fines que los estadísticos.

El hecho de que la información se recopile con fines estadísticos implica que la misma no puede ser suministrada ni publicada sino en compilaciones de conjunto. Esto significa que de ninguna forma resulte posible identificar a las unidades estadísticas (personas, empresas, hogares, etc.).

Los datos se publicarán de manera tal que no se puede deducir el valor numérico correspondiente a una determinada unidad estadística que se sabe que integra el universo que se presenta.

Las bases de datos que se suministren deben estar construidas innominadas y cuando en algún sector económico o zona geográfica haya menos de tres registros, estas unidades deberán agruparse en otras categorías de forma tal de evitar la posible individualización o deducción de los valores individuales.

\section{ANÁLISIS, RESULTADOS Y DISCUSIÓN}

\section{METODOLOGÍA}

En primer lugar, se llevó a cabo una revisión bibliográfica sobre la Caminabilidad y otros conceptos relacionados al tema en estudio. Luego de examinar las investigaciones, 
independientemente de sus objetivos, se seleccionó aquellas variables que tengan una influencia destacada en el área de estudio. Este paso es primordial, ya que la selección de una u otra variable dependerá del entorno y de sus características.

Para los efectos de este trabajo, en general, se desarrolló una metodología de análisis que ayudó a determinar las áreas del centro de Río Gallegos más adecuadas para caminar y las que necesitan un mejoramiento.

Una vez definido el concepto de Caminabilidad, se diseñó una planilla de campo, donde la unidad de análisis es el lote (domicilio). Se definieron las variables, que son un grupo de elementos a tener en cuenta al momento de la observación directa: veredas, entrada de vehículos, ochavas, columnas, rampas, escalones, cercos, etc.

Para llevar a cabo la digitalización y posterior cartografía se utilizó el software ARC VIEW Versión 3.3.

Para definir el área de estudio, se tomó como referencia la Ordenanza Municipal de Río Gallegos $N^{\circ}$ 2147-HCD-98 (ordenanza relativa a la 3259), la cual define, en el artículo $3^{\circ}$ de delimitación de las zonas, el área comercial central de Río Gallegos: "Comprende la totalidad de las siguientes Manzanas: 118, 127, 138, 147, 158, 168, 179, 178, 169, 157, 148, 137,128, y 117 y todas las parcelas frentistas a la calle Magallanes (...) Alcorta (...) Comodoro Rivadavia y su continuación 25 de Mayo (...) Don Bosco (...) Zapiola (...) y Entre Ríos”. (Fig. 2)

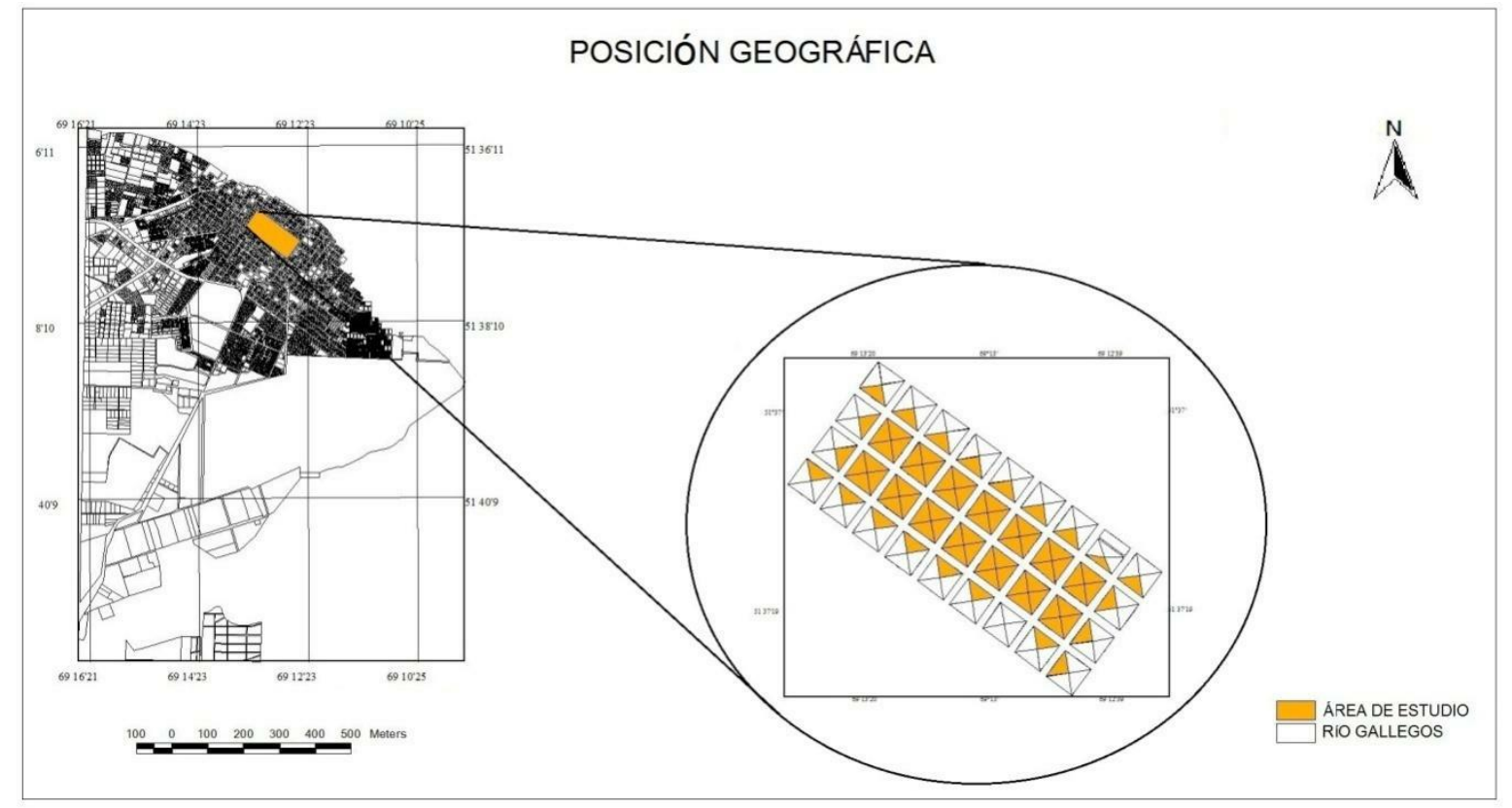

Figura 2: Posición geográfica del área de estudio en Río Gallegos.

Fuente: Elaborado por Puca, M. F., Valdebenito, Y. y Aceves, K. L.

El área de estudio se encuentra limitada por las siguientes calles Entre Ríos y Magallanes, Alberdi y Alcorta, 25 de mayo y Comodoro Rivadavia, Zapiola y Don Bosco (fig. 3). 


\section{CENTRO DE RÍO GALLEGOS}

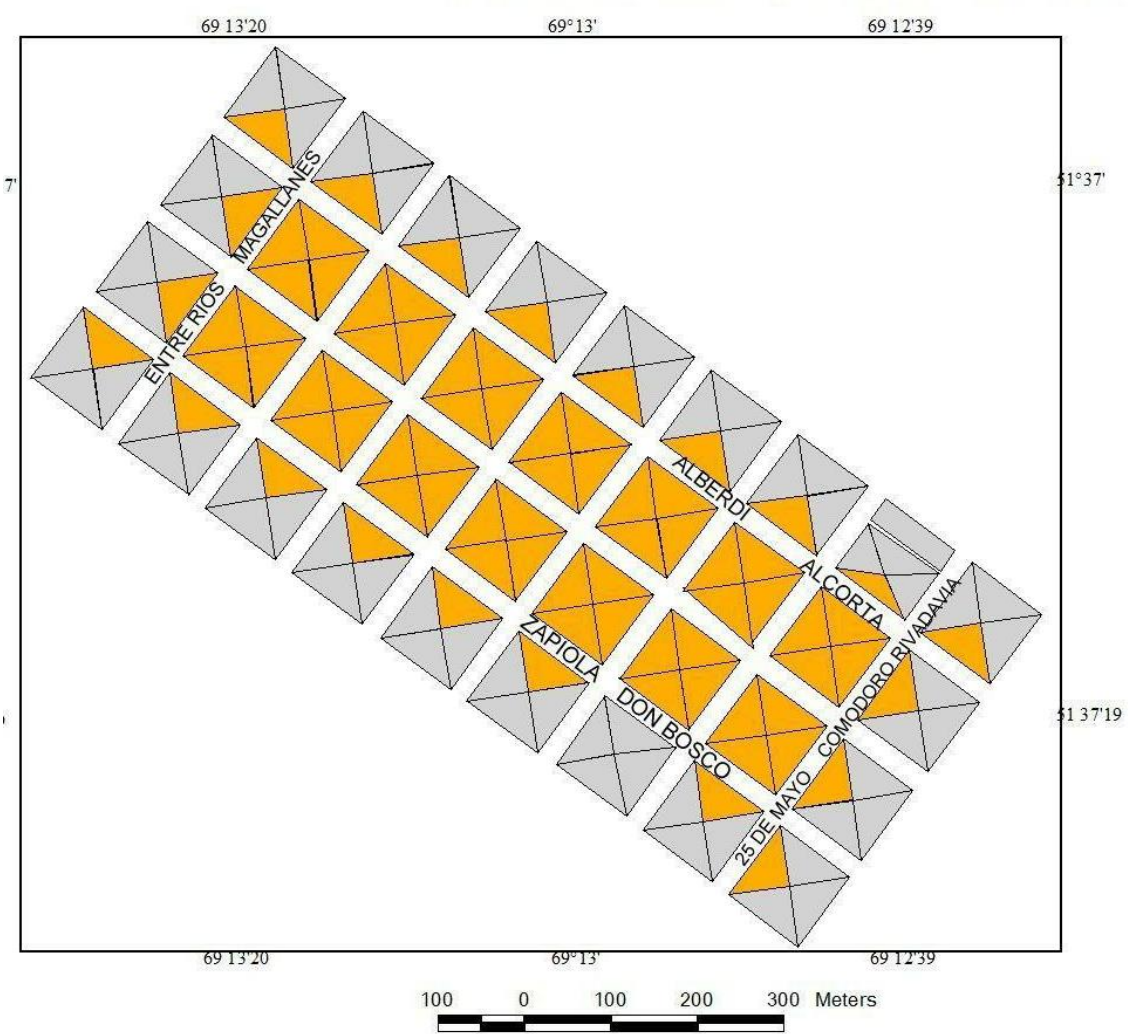

$\stackrel{N}{A}$

ÁREA DE ESTUDIO

$\mathrm{SI}$

NO

Figura 3: Área Comercial Central de Río Gallegos. Área de estudio.

Fuente: Elaborado por Puca, M. F., Valdebenito, Y. y Aceves, K. L.

El área de estudio fue dividida en cuatro secciones, que corresponden a cada observador, para relevar los datos, elegido de manera azarosa. La organización del mismo se observa en el siguiente croquis (Figura 4).

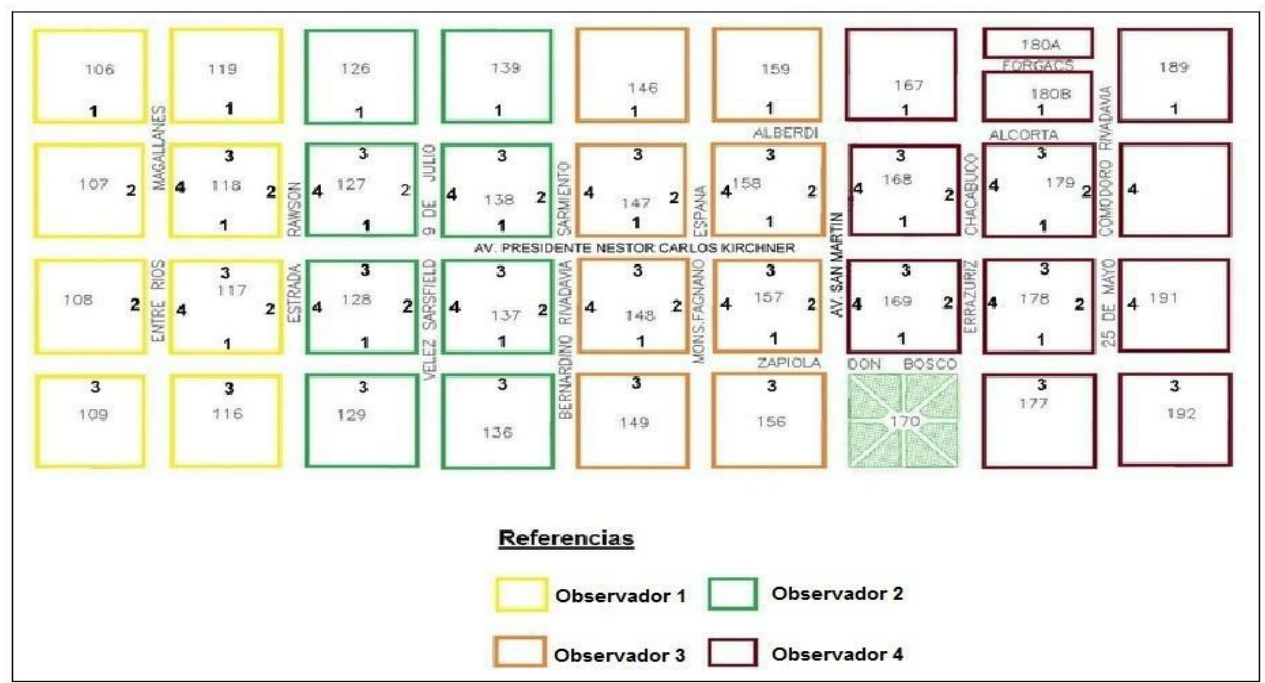

Figura 4: Croquis del área en estudio con el número de observadores y manzanas correspondientes.

Fuente: Elaboración propia, con base cartográfica de la Municipalidad de Río Gallegos.

Mediante esta organización, se prosiguió con el relevamiento de información del área designada, a través de diferentes observadores, considerándose como "aquel que observa o mira un objeto con mucha atención y detenimiento para adquirir algún conocimiento sobre su comportamiento o características" según "Diccionario Léxico Oxford". Con el objetivo de 
completar las planillas de campo previamente confeccionadas en gabinete. Para la creación del índice de Caminabilidad, se relevaron 77 lados o frentes y 35 manzanas.

\section{Creación de un indicador de Caminabilidad a partir de obstáculos, aplicado al área comercial central de Río Gallegos}

Mediante la observación directa, se realiza un conteo manual de obstáculos por domicilio: estados de las aceras, presencia de rampas, presencia de recipientes de basura, estados de los cordones, cantidad de árboles, estado general de la jardinería en la vereda (canteros), presencia de carteles publicitarios, señalización oficial, accesibilidad de discapacitados a locales comerciales, accesibilidad al transporte público, alumbrado público, y obstáculos específicos que alteran la movilidad libre del peatón. Una vez identificados los obstáculos, se crea un intervalo de obstáculos.

Como resultado, el máximo de obstáculos encontrados fueron 14. Para poder clasificar el estado del área, se designaron valores cualitativos (muy bueno, bueno, etc.) según la cantidad de obstáculos. Por lo tanto, se obtienen los siguientes intervalos de conteo manual (Tab. 1).

\begin{tabular}{cc} 
Muy bueno & $0-2$ \\
\hline Bueno & $3-5$ \\
\hline Regular & $6-8$ \\
\hline Malo & $9-11$ \\
\hline Muy malo & $12-14$
\end{tabular}

Tabla 1: Intervalo de obstáculos por conteo manual Fuente: Elaborado por Puca, M. F., Valdebenito, Y. y Aceves, K. L.

Estos intervalos son la base fundamental del indicador de Caminabilidad. Esta base se utiliza para poder procesar la información y aplicar herramientas informáticas.

En gabinete, se llevó a cabo el procesamiento de la información por medio de la planilla de cálculo "Microsoft Office Excel". Una vez volcada la información, se utilizó la herramienta "count color" (contar color), la cual permite contar los obstáculos de las celdas pintadas de color, en nuestro caso rojo, obteniendo de manera automática el total de obstáculos por domicilio.

Debido al secreto estadístico, no se puede publicar información de cada domicilio (lote), por lo tanto, se llevó a cabo un ajuste metodológico y se divide la manzana en lados. Se evalúa la Caminabilidad en base a los lados de cada cuadra, enumerándolos en sentido antihorario, y se tomó como inicio de conteo el lado más al sur (Fig. 5). 


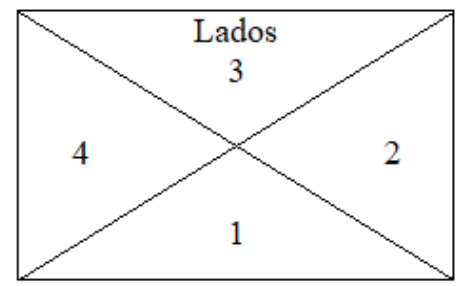

Figura 5: Lados de manzanas

Fuente: Elaborado por Puca, M. F., Valdebenito, Y. y Aceves, K. L.

De esta manera se construye el índice para evaluar la Caminabilidad en el área de estudio.

Luego de obtener, en nuestra base de datos en la planilla de cálculos Microsoft Office Excel, la columna del total de obstáculos (por domicilio), se proyecta en otra columna, valoración general (Fig. 6) de los obstáculos de la siguiente manera:

\section{Fórmula:}

$=+\mathrm{SI}(\mathrm{O}(\mathrm{BZ7}=0 ; \mathrm{BZ7}=1 ; \mathrm{BZ7}=2) ; " \mathrm{MUY}$

BUENA";+SI(O(BZ7=3;BZ7=4;BZ7=5);"BUENA";+SI(O(BZ7=6;BZ7=7;BZ7=8);"REGUL AR";+SI(O(BZ7=9;BZ7=10;BZ7=11);"MALA";+SI(O(BZ7=12;BZ7=13;BZ7=14);"MUY MALA";"ERROR")))))

\begin{tabular}{|c|c|c|c|c|c|c|c|c|c|c|c|c|c|c|c|c|}
\hline CA7 & \multicolumn{2}{|c|}{$\cdot c$} & $=+S I(O(B Z 7=0 ;$ & $: 1 ; B Z 7$ & JY BB & (O)BZ7 & $7=4$ & -5);"BUENA" & $+\mathrm{SI}(\mathrm{O}(\mathrm{BZ7}$ & $B Z 7=7 ; B Z 7=8) ; "$ & ;"REGULAR";+c & $-S I O(B Z 7=9 ; B Z 7$ & $=10 ; B Z 7=1$ & );"MALA"; & $3 Z 7=1$ & $=4$ \\
\hline BN & $\mathrm{BC}$ & $B P$ & $B Q$ & BR & BS & BT & BU & BV & BW & $\mathrm{BX}$ & $B Z$ & CA & СВ & cc & $C D$ & ( \\
\hline \multirow{2}{*}{$\begin{array}{l}\text { veredas } \\
\text { marcadas para } \\
\text { ciegos } \\
\end{array}$} & \multicolumn{2}{|c|}{ Transporte publico } & \multicolumn{5}{|c|}{ Vulnerabilidad } & \multicolumn{3}{|c|}{ Condiciones naturales } & \multirow{2}{*}{$\begin{array}{c}\text { Total de } \\
\text { obstáculos }\end{array}$} & \multirow{2}{*}{\multicolumn{2}{|c|}{$\begin{array}{c}\text { Valoración general de } \\
\text { caminabilidad }\end{array}$}} & \multirow{3}{*}{ Lugar } & & \\
\hline & Tipo & Estado & $\begin{array}{c}\text { Obstáculos } \\
\text { al peatón }\end{array}$ & Lugar & Tipo & \multirow[t]{2}{*}{$\begin{array}{c}\text { Riesgos al } \\
\text { peatón }\end{array}$} & \multirow{2}{*}{ Lugar } & \multirow{2}{*}{ Viento } & Sol & Hora & & & & & & \\
\hline & & & & & & & & & & & & & & & & \\
\hline & no & - & 0 & & & & & si & no & & 9 & MALA & & peluquer & on tra & \\
\hline & no & - & 1 & & & & & si & no & & 4 & BUENA & & & & \\
\hline & no & - & 0 & & & & & si & no & & 4 & BUENA & & & & \\
\hline & no & - & 0 & & & & & si & no & & 4 & BUENA & & & & \\
\hline & & & & & & & & & & & & & & & & \\
\hline & & & & & & & & & & & & & & & & \\
\hline & & & & & & & & & & & & & & & & \\
\hline & & & & & & & & & & ESTADO & CANTIDAD & $\%$ & & & & \\
\hline & & & & & & & & & & MUY MALA & 0 & 0 & & & & \\
\hline & & & & & & & & & & MALA & 1 & 25 & & & & \\
\hline & & & & & & & & & & REGULAR & 0 & 0 & & & & \\
\hline & & & & & & & & & & BUENA & 3 & 75 & & & & \\
\hline & & & & & & & & & & MUY BUENA & 0 & 0 & & & & \\
\hline & & & & & & & & & & & & 100 & & & & \\
\hline & & & & & & & & & & & & & & & & \\
\hline
\end{tabular}

Figura 6: Valoración general

FUENTE: Elaborado por Puca, M. F., Valdebenito, Y. y Aceves, K. L.

A continuación se utilizó la siguiente fórmula, para obtener la cantidad de la "valoración general", es decir, cuenta la cantidad de "Buena", "mala", "regular", etc., que hay en el lado relevado. 


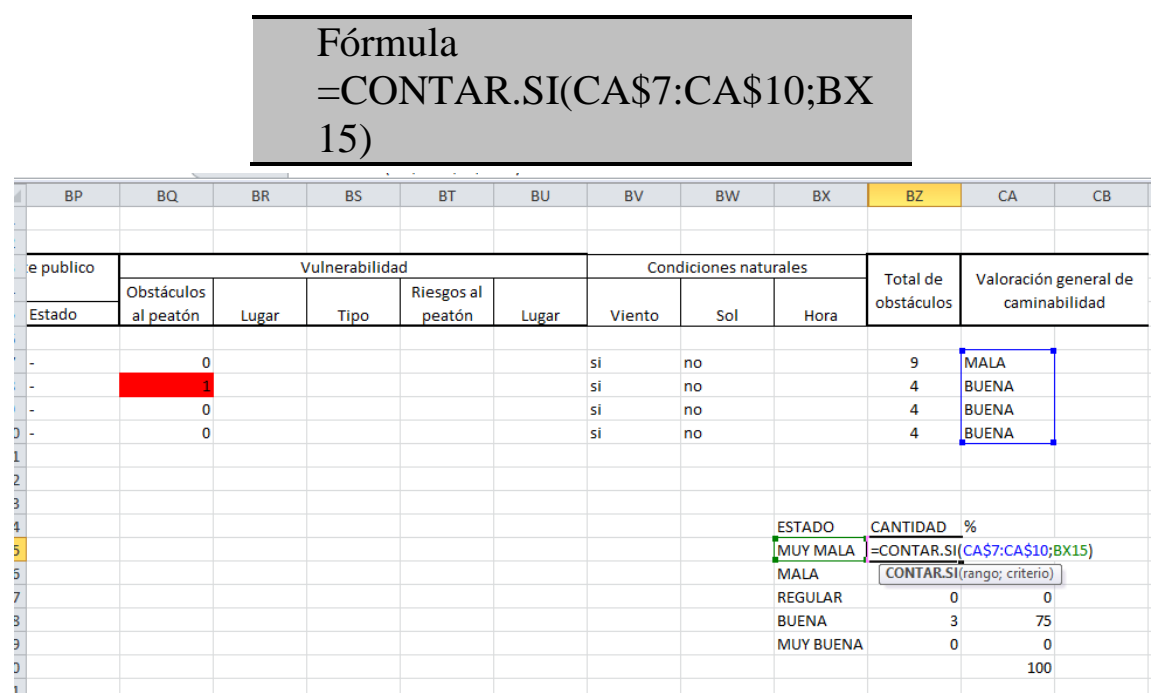

A partir de esta fórmula se obtiene el porcentaje de Caminabilidad del lado. Cálculo de porcentaje:

Fórmula:

$=+\mathrm{BW} 14 / \mathrm{SUMA}(\mathrm{BW} \$ 12: \mathrm{BW} \$ 16)^{*} 100$

\begin{tabular}{|c|c|c|c|c|c|c|c|c|c|c|c|c|c|c|}
\hline \multirow{3}{*}{\begin{tabular}{|c|} 
BN \\
veredas \\
$\begin{array}{c}\text { marcadas para } \\
\text { ciegos }\end{array}$ \\
\end{tabular}} & BO & BP & 80 & RR & BS & BT & BH & BV & RW & $\mathrm{Bx}$ & \multirow{3}{*}{$\begin{array}{c}\text { BY } \\
\text { Observacio } \\
\text { nes }\end{array}$} & \multirow{3}{*}{$\begin{array}{c}\text { BZ } \\
\begin{array}{c}\text { Total de } \\
\text { obstáculos }\end{array} \\
\end{array}$} & \multirow{3}{*}{\multicolumn{2}{|c|}{$\begin{array}{c}\text { CA CB } \\
\text { Valoración general de } \\
\text { caminabilidad }\end{array}$}} \\
\hline & \multirow{2}{*}{\multicolumn{2}{|c|}{ Transporte publico }} & \multicolumn{5}{|c|}{ Vulnerabilidad } & \multicolumn{3}{|c|}{ Condiciones naturales } & & & & \\
\hline & & Estado & \begin{tabular}{|c|} 
Obstáculos \\
al peatón
\end{tabular} & Lugar & Tipo & \begin{tabular}{|c|} 
Riesgos al \\
peatón
\end{tabular} & Lugar & Viento & Sol & Hora & & & & \\
\hline No & No & - & - & - & - & - & - & si & No & $14: 20$ & & \multicolumn{3}{|c|}{4 BUENA } \\
\hline No & No & - & 4 & vereda & es, depresiol & tropiezos & vereda & SI & No & $14: 25$ & & \multirow{2}{*}{\multicolumn{2}{|c|}{$\begin{array}{l}8 \text { REGULAR } \\
2 \text { MUY BUENA }\end{array}$}} & \\
\hline \multirow[t]{11}{*}{ Si } & No & - & - & - & - & - & - & si & No & $14: 25$ & & & & \\
\hline & & & & & & & & & & & & & & \\
\hline & & & & & & & & & & & & & & \\
\hline & & & & & & & & & & & & & & \\
\hline & & & & & & & & Estado & Contic & ref & & & & \\
\hline & & & & & & & & \begin{tabular}{|l|} 
MUY MALA \\
\end{tabular} & Cantioad & 0 & & & & \\
\hline & & & & & & & & MALA & c & 0 & & & & \\
\hline & & & & & & & & REGULAR & & 33.3. & & & & \\
\hline & & & & & & & & \begin{tabular}{|l} 
MUY BUENA \\
\end{tabular} & & 33.3 & & & & \\
\hline & & & & & & & & BUENA & 1 & 33.3 & & & & \\
\hline & & & & & & & & & & & & & & \\
\hline & & & & & & & & & & & & & & \\
\hline
\end{tabular}

Al obtener los porcentajes antes mencionados y para alcanzar una valoración general, que no refleje el estado por domicilio, se considera solo el porcentaje más elevado de cada lado. Este dato general del lado, se utiliza para confeccionar la planilla del programa ARC VIEW, el cual proporciona una nueva base de datos, con el objetivo de cartografiar el índice de Caminabilidad.

Esta planilla del ARC VIEW, facilita automáticamente la cantidad de lados que tienen estado muy bueno, bueno, regular, malo, y muy malo. Y en base a esos datos, se pudo calcular un porcentaje de manera manual, teniendo en cuenta que el $100 \%$ es de 77 lados, con el objetivo de obtener cartográficamente el índice de Caminabilidad de los lados, por manzana.

\section{RESULTADOS}

En cuanto a la valoración general de la Caminabilidad de área comercial central de Río Gallegos, la información obtenida, fue procesada en una base de datos mediante una planilla de Excel, a través de las fórmulas, ya mencionadas en la metodología de este trabajo, donde se 
confeccionó el índice de Caminabilidad (Tabla 2) y de esta manera se obtuvieron los siguientes resultados:

\begin{tabular}{|c|c|}
\hline $\begin{array}{l}\text { VALORACIÓN } \\
\text { GENERAL DE LA } \\
\text { CAMINABILIDAD }\end{array}$ & PORCENTAJES \\
\hline MUY BUENO & $10,39 \%$ \\
\hline BUENO & $46,75 \%$ \\
\hline REGULAR & $37,66 \%$ \\
\hline MALO & $2,60 \%$ \\
\hline MUY MALO & $2,65 \%$ \\
\hline
\end{tabular}

Tabla 2: Indicador de Caminabilidad Fuente: Elaborado por Puca, M. F., Valdebenito, Y. y Aceves, K. L.

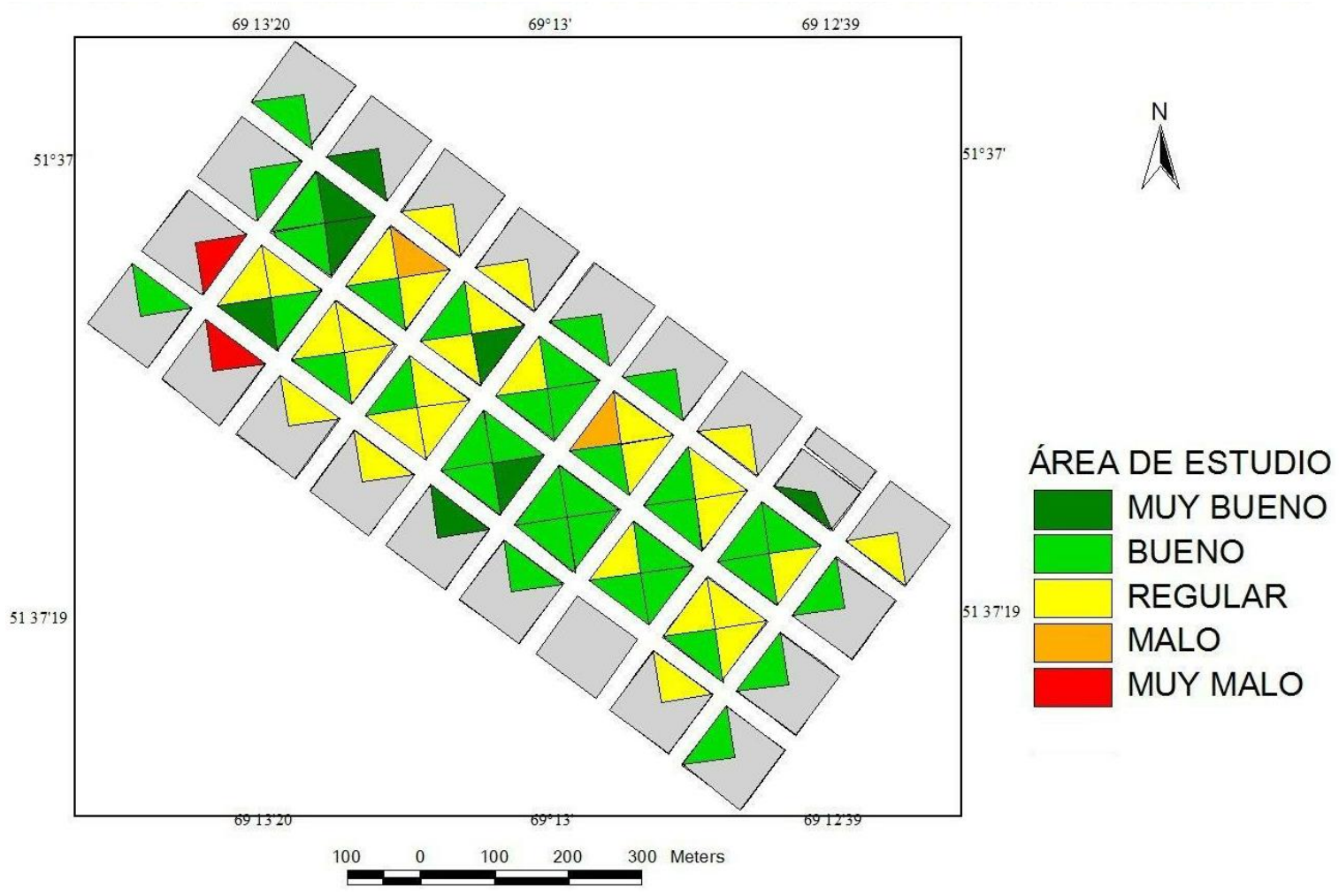

Figura 8: Indicador de Caminabilidad del Centro de Río Gallegos Fuente: Elaborado por Puca, M. F., Valdebenito, Y. y Aceves, K. L.

En el área de estudio, predomina el rango correspondiente a la valoración "BUENO" en cuanto a la Caminabilidad, representado con un $47 \%$. Esto indica que varios lados de las cuadras no intervienen ningún tipo de obstáculos para la Caminabilidad del peatón.

En contraposición, se observa los estados "MALO" y "MUY MALO", como los porcentajes más bajos, representan un $2 \%$, y $3 \%$ respectivamente, en las calles España (entre Av. Presidente Dr. Néstor Carlos Kirchner y Alberdi), Alberdi (entre Rawson y 9 de julio), Entre 
Ríos (entre Av. Presidente Dr. Néstor Carlos Kirchner y Zapiola) y Zapiola (entre Estrada y Entre Ríos).

Se puede destacar las variables que predominan en este estado, siendo estos, los distintos tipos de obstáculos, tales como baldosas rotas, ausencia de baldosas, depresiones, ausencia de recipientes de basura, no hay cordón pintado en la esquina, el estado del cordón es malo, no posee rampas en la acera (vereda), acera en mal estado (Figura 9,10 y 11). Por lo tanto, la vereda se convierte en un obstáculo, con serios riesgos al peatón. Además, en las en las veredas, circundantes además de poseer las mismas variables que en el anterior, se destaca también rampa frontal y lateral en mal estado, entrada al comercio con escalón, postes de luz en mal estado, las veredas no están con la señalización adecuada, casilla de taxi ubicada sobre el solado, en mal estado y se observó excesiva basura.

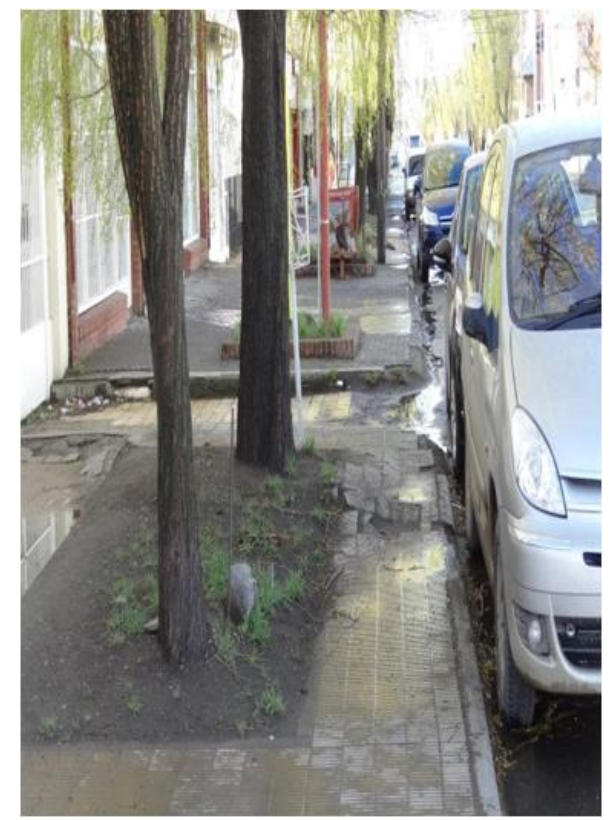

Figura 9: Calle Entre Ríos (al 100, vereda par)

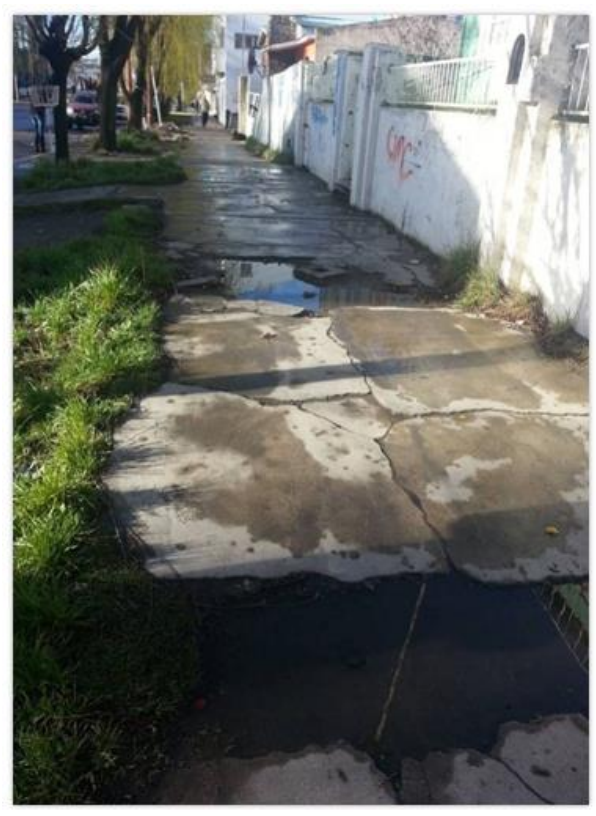
Figura 10: Calle Entre Ríos (al 100 vereda impar) Fuente: Fotografía de salida de campo, propiedad de Puca, M. F., Valdebenito, Y. y Aceves, K. L

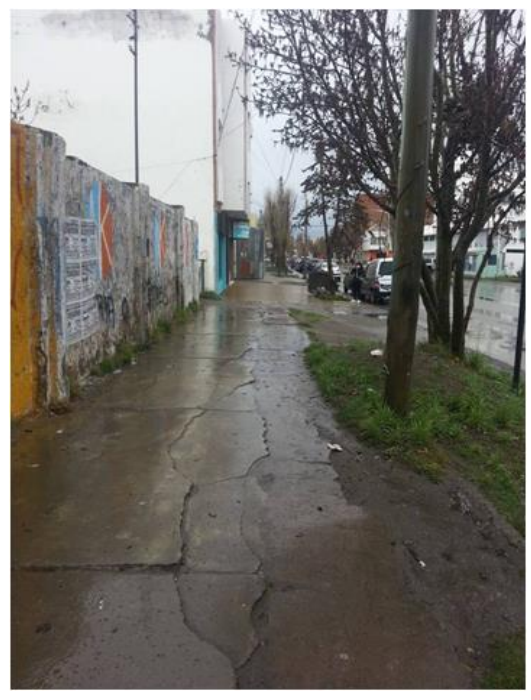

Figura 11: Calle Zapiola (al 400) 
Fuente: Fotografía de salida de campo, propiedad de Puca, M. F., Valdebenito, Y. y Aceves, K. L

\section{DISCUSIÓN}

Los resultados obtenidos arrojan que, el indicador de Caminabilidad con mayor porcentaje corresponde al estado BUENO con el 46,75\%, seguido por REGULAR con un 37,66\%. Solo el $10,39 \%$ es óptimo (MUY BUENO).

Una cuestión a tener en cuenta es que, el indicador de Caminabilidad en el área de estudio no es constante. Existen sectores en donde la valoración es "MUY BUENO" pero en otros no. Entonces, si se quisiera diseñar un circuito apropiado para llevar a cabo las actividades de los transeúntes en el Área Central analizada, no se podría realizar.

Además, las veredas del área de estudio presentan varios obstáculos como accesos a distintos locales u oficinas, que no son los adecuados a las normativas o el caso de la jardinería en general, que posee un mantenimiento precario.

Es importante aclarar que este indicador de valoración fue diseñado teniendo en cuenta las condiciones de la ciudad, por lo tanto no se puede utilizar en otros estudios, sí la metodología pero no los valores obtenidos.

\section{CONCLUSIÓN}

En cuanto a todo el recorrido del trabajo realizado, se pudo cumplir con los objetivos planteados, ya que se logró indagar, conocer y determinar, a partir de parámetros, la valoración de la Caminabilidad en el Área Comercial Central de Río Gallegos.

A partir de lo expuesto y en congruencia con nuestra hipótesis: "la Caminabilidad no es óptima en el centro de Río Gallegos", se determina que se cumple la hipótesis planteada. Puesto que, en base a los métodos planteados, se llegó a la conclusión que la Caminabilidad no es óptima en el área de estudio.

Este informe permite tomar consciencia sobre el estado del sector del área de estudio de la ciudad, ayudar a la planificación urbana y el cuidado del Área Comercial Central. Para darle una valoración a este espacio por donde transitan muchas personas constantemente.

Como equipo de trabajo, queremos destacar que es un primer aporte teórico y metodológico con respecto a la Caminabilidad en Río Gallegos, por lo que esperamos que se pueda utilizar como base para futuras investigaciones y se lo considere a la hora de tomar decisiones por parte del gobierno municipal.

\section{AGRADECIMIENTOS}

A la Mg. Nora Muñoz, docente de la cátedra "Lingüística I" de la UNPA UARG, por su orientación sobre los conceptos de Caminabilidad y transitabilidad.

A la Lic. Ana María Cornaglia, docente de la cátedra "Estadística para Ciencias Sociales" de la UNPA UARG, por su ayuda y asesoramiento para definir la unidad de análisis.

Al Lic. Cristian Ampuero, por facilitarnos información y archivos shapefile para llevar a cabo la digitalización y generar la cartografía de la ciudad de Río Gallegos. 
Al Consejo Profesional de la Agrimensura - Ingeniería - Arquitectura (CPAIA), quienes nos brindaron ordenanzas municipales.

Y por último, pero no menos importante, a nuestras familias, quienes nos brindaron su apoyo incondicional, desde un principio para poder hacer esto posible.

\section{REFERENCIAS}

AISENBERG, B., y ALDEROQUI, S. (2007). "Didáctica de las ciencias sociales". Cap. 1. Buenos Aires. Ed. Paidós.

ANDER - EGG, E. (1995, 2001). "Técnicas de Investigación Social”. Buenos Aires. Ed. Lumen/Hvmanitas.

BEZERRA, B., y TAPIA, S. (2004). La Caminabilidad de las ciudades como un reflejo del desarrollo sustentable. En Avances en energías renovables y Medio Ambiente. Vol 8 No. 1. Argentina". Web: http://sedici.unlp.edu.ar/handle/10915/81609

Blog Ciudades emergentes y sostenibles. Banco Interamericano de Desarrollo. Web: https://blogs.iadb.org/ciudades-sostenibles/es/

CÁCERES, A., y GARCÍA, A. (2004). "Diferenciación interna del espacio geográfico de Río Gallegos: Estudio preliminar”. Río Gallegos. Párrafos Geográficos. Año III N³.

CÁCERES, A. et al. (2016). "Posición Geográfica de Río Gallegos de la Patagonia Austral". Universidad Nacional de la Patagonia Austral, Unidad Académica Río Gallegos. Instituto de Ciencias del Ambiente, Sustentabilidad y Recursos Naturales (ICASUR). Instituto de Trabajo, Economía y Territorio (ITET).

Código de Edificación. Código de Edificación. Tomo 1 y 2. Ordenanzas y decretos. Honorable Concejo Deliberante. Ciudad de Río Gallegos. Argentina.

Enciclopedia de ciencia y tecnología en Argentina. Concepto de ochava. Web: http://cytar.com.ar/cyt-ar/index.php/Ochava

FOSCHIATTI, A. M. (2004). Vulnerabilidad global y pobreza. Universidad Nacional del Nordeste. Web: http://hum.unne.edu.ar/revistas/geoweb/Geo2/contenid/vulner6.htm.

FONTÁN SUÁREZ, S. (2012). Índice de Caminabilidad aplicado a la Almendra Central de Madrid. Universidad Complutense de Madrid. España. Web: https://eprints.ucm.es/20074/1/Tfm_sofia_fontan.pdf

LESLIE, E. et al. (2005). "Walkability of local communities: Using geographic information systems to objetively asses relevant environmental attributtes". Health and Place, 13, 111-122. https://doi.org/10.1016/j.healthplace.2005.11.001

LEAL, A. (2012). Medición de la Caminabilidad y la infraestructura peatonal: el caso de Manila, Filipinas. VIII Congreso Internacional de Transporte Sustentable, México.

Ley de Tránsito No. 24.449. Sancionada: Diciembre 23 de 1994. http://servicios.infoleg.gob.ar/infolegInternet/anexos/0-4999/818/texact.htm.

Leyes y decretos de la seguridad vial Argentina 2012. Pág. 15

MINAYA JAQUE, O. (2009). Informe sobre Tratamiento de Veredas. Facultad de Arquitectura. Universidad César Wallejo. https://es.slideshare.net/Hamnetzuelo/tratamiento-de-veredas

OWEN et al. (2007). "Neighborhood Walkability and the walking behavior of Australian adults". American Journal of Preventive Medicine, 33, 387-395.

OWEN et al. (2004). "Understanding enviromental influences on walking". Review and research agenda. American Journal of Preventive Medicine, 27, 67-76.

Ordenanza 3259 de Zonificación de Río Gallegos. 2012. Ordenanzas y decretos. Carpeta 76. Honorable Concejo Deliberante. Ciudad de Río Gallegos. Provincia de Santa Cruz. Argentina. 
PARDINAS, F. (1999). “Metodología y Técnicas de Investigación en ciencia sociales”. Cap. II, IV, V, VI. México. Ed. Siglo veintiuno editores.

Real Academia Española.

Reglamentación General de la Ley N 24.449 de Tránsito y Seguridad Vial. Anexo 1. Web: http://www.agvp.gov.ar/Educacion\%20Vial/Ley\%20de\%20Transito/Anexos/ANEXO $\% 201 . p d f$

SAELENS et al. (2003). "Environmental correlates of walking and cycling: findings from the transportation, urban design, and planning literatures". Páginas 80-91

SIERRA BRAVO, R. (1998). "Técnicas de Investigación Social. Teorías y ejercicios. Madrid. Ed. Paraninfo. S.A.

Sistema de Señalización Vial Uniforme. Anexo al artículo 22. Anexo L. Web: http://www.agvp.gov.ar/Educacion\%20Vial/Ley\%20de\%20Transito/Anexos/ANEXO $\% 20 \mathrm{~L} . p d f$

UCHA, F. (2010). Definición de Transeúnte. Web: https://www.definicionabc.com/general/transeunte.php

ZALAZAR, F. (2014). Condiciones y Normas que debe tener una vereda. Web: https://prezi.com/ssoa1zjewnmv/la-pendiente-longitudinal-de-las-veredas-seradeterminada-p 